\title{
TINJAUAN KONSEP FEMINISME PADA BANGUNAN NATASHA SKIN CARE BANDUNG SEBAGAI PUSAT KECANTIKAN
}

\author{
${ }^{1}$ Almira Muthi Faliha, ${ }^{2}$ Yeptadian Sari \\ ${ }^{1}$ Universitas Muhammadiyah Jakarta, Jakarta, Indonesia \\ almiramuthi@gmail.com ${ }^{1}$
}

\author{
Informasi Naskah \\ Diterima: 19/04/2021; Disetujui terbit: 14/06/2021; Diterbitkan: 30/06/2021; \\ http://journal.uib.ac.id/index.php/jad
}

\begin{abstract}
ABSTRAK
Perkembangan zaman yang pesat membuat teknologi semakin canggih, hal itu membuat sumber informasi dan komunikasi dapat diterima secara cepat, karena adanya peran internet. Pengaruhnya terhadap masyarakat dapat berdampak baik dan juga buruk untuk kelangsungan pola hidup dalam berinteraksi sosial. Dampak buruk yang sering dialami perempuan biasanya timbul rasa tidak percaya diri dalam penampilannya saat berinteraksi sosial, permasalahan tersebut membuat perempuan harus berusaha untuk mencari cara agar mereka bisa percaya diri dengan berpenampilan menarik sesuai dengan harapan mereka. Oleh karena itu, dibutuhkannya suatu tempat pusat kecantikan yang menerapkan konsep arsitektur feminisme dengan sifat keperempuanan. Adapun studi kasus yang akan dibahas dalam penelitian ini yaitu Natasha Skin Care yang lokasinya berada di Jl.Supratman No. 84 Bandung, sedangkan metode yang digunakan adalah deskriptif kualitatif. Hasil dari penelitian ini dapat dikatakan bahwa bangunan Natasha Skin Care hampir mendekati penerapan konsep arsitektur feminisme yang sesuai dari beberapa kriteria yaitu dalam pemilihan material pada fasad, warna pada interior dan eksteriornya serta pembagian ruang yang jelas antara ruang publik dan privat.
\end{abstract}

Kata Kunci: Interaksi Sosial, Perempuan, Arsitektur feminisme, Pusat Kecantikan

\section{ABSTRACT}

The rapid development of the times makes technology more sophisticated, it makes information and communication sources accepted quickly, because of the role of the internet. Its influence on society can have both good and bad impacts for the continuity of life patterns in social interaction. The bad impact that is often experienced by women is usually a feeling of insecurity in their appearance when interacting socially, this problem makes women have to try to find ways so that they can be confident by looking attractive according to their expectations. Therefore, we need a place of beauty center that applies the concept of feminism architecture with feminine characteristics. The case study that will be discussed in this research is Natasha Skin Care, which is located on Jl. Supratman No. 84 Bandung, while the method used is descriptive qualitative. The results of this study can be said that the Natasha Skin Care building is almost close to the application of the concept of feminist architecture according to several criteria, namely in the selection of materials on the facade, the color of the interior and exterior and a clear division of space between public and private spaces.

Keyword: Social Interaction, Women, Feminist Architecture, Beauty Center

\section{Pendahuluan}

Pada era globalisasi, teknologi semakin berkembang dengan cepat baik teknologi informasi maupun komunikasi yang dapat mempengaruhi pola hidup masyarakat dalam berinteraksi sosial. Teknologi yang semakin canggih membuat sumber informasi dan komunikasi dapat diterima secara cepat, karena adanya peran internet, hal itu berbanding lurus dengan tingkat kebutuhan manusia untuk keberlangsungan hidupnya. Namun internet bisa berdampak baik dan juga bisa berdampak buruk dalam pola hidup masyarakat. Misalnya, setelah mendapatkan informasi mengenai seputar kecantikan melalui media 
sosial. Pengaruh dalam berpenampilan bisa berdampak baik seperti timbulnya rasa percaya diri seorang perempuan ketika saat berinteraksi sosial, karena sejatinya setiap manusia terutama perempuan, ingin berpenampilan sempurna saat berinteraksi sosial. Sedangkan pengaruh buruknya perempuan seringkali kehilangan rasa percaya diri dalam berperan aktif di hadapan banyak orang atau dalam berinteraksi sosial (Sya'bania, Mauliani \& Sari,2019). Tidak terkadang, perempuan berlomba-lomba untuk mengekspresikan dirinya agar berpenampilan menarik sesuai dengan ekspetasinya (Thompson,2008). Oleh karena itu, untuk mengatasi permasalahan tersebut, dibutuhkannya suatu tempat pusat kecantikan yang menunjang perempuan dengan sifat feminimnya. Selain itu feminisme juga dikenal sebagai gerakan perempuan yang menuntut kesetaraan antar laki-laki.

Menurut Sumiarni (2004) yang dikutip oleh Silaban \& Punuh (2011) feminisme berasal dari kata latin yaitu femina yang artinya sifat yang cenderung dimiliki perempuan. Salah satunya, bahwa setiap perempuan pasti ingin tampil sempurna saat berinteraksi sosial. Selain itu feminisme juga disebut sebagai sebuah gerakan perempuan yang menuntut kesetaraan terhadap laki-laki. Dapat dikatakan bahwa semua itu adalah kebebasan perempuan untuk menyuarakan hak-haknya. Bentuk kaum perempuan dalam menutut kesetaraan, tidak terkecuali dalam segi arsitekturnya, yang mana pada era postmodern kebanyakan pria memegang peran penting dalam perubahan arsitektur, sehingga muncul penolakan dalam gerakan perempuan yang disebut feminisme. Melihat hal tersebut, arsitek perempuan menuntut kesetaraan kedudukan untuk membuat kaum perempuan merasa sejajar terhadap perubahan arsitektur.

Berdasarkan pembahasan diatas maka perlu tinjauan analisis terhadap penerapan konsep arsitektur feminisme untuk dapat memahami langkah-langkah yang perlu diperhatikan agar perempuan merasa percaya diri dalam interaksi sosial. Oleh karena itu, penulis melakukan penelitian dengan judul "Tinjauan Konsep Feminisme Pada Pusat Kecantikan" agar dapat memahami gambaran dalam menerapkan konsep feminisme pada bangunan pusat kecantikan.

\section{Kajian Pustaka}

Kajian Pustaka pada penelitian ini membahas mengenai latar belakang feminisme, pengertian arsitektur feminisme, penerapan konsep arsitektur feminisme, pengertian pusat kecantikan antara lain:

\subsection{Latar Belakang Feminisme}

Feminisme adalah sebuah gerakan perempuan untuk menuntut kesetaraan dengan lakilaki. Lahirnya gerakan feminisme berawal dari asumsi bahwa perempuan diperlakukan secara tidak adil dan selalu dinomor dua kan, dengan berbagai diskriminasi dalam pendidikan, politik, sosial dan sebagainya, tidak hanya itu gerakan ini muncul karena adanya sistem patriarki yang mana kedudukan laki-laki lebih tinggi dibandingkan perempuan. Perlakukan seperti ini yang menimbulkan perempuan membuat aksi gerakan feminisme. Pada tahun 1848 feminisme digunakan sebagai nama sebuah gerakan sosial yang membahas mengenai hak-hak perempuan di New York oleh Elizabeth Candy Stanton dan kawannya, karena pada saat itu perempuan mengalami perlakuan tidak adil dengan tidak mempunyai hak dalam memilih. Perempuan di sama ratakan dengan anak dibawah umur dengan tidak diperbolehkan mengikuti pemilihan umum.

Pada abad yang sama, dimana Indonesia masih dalam wilayah kerajaan. Feminis asal Indonesia RA.Kartini melalui surat menyuratnya dengan feminis asal belanda Stella Zeehandelaar bertujuan untuk membentuk kemerdekaan Indonesia. Surat-surat tersebut digabungkan menjadi sebuah buku Habis Gelap Terbitlah Terang, yang mengatakan

91 I AD- Vol.02/No.01, Juni 2021 
bahwa setiap manusia akan mengalami masa-masa sulit, tetapi juga akan merasakan masa-masa membahagiakan. Dimana seorang feminis asal Indonesia RA.Kartini mengalami perlakuan tidak adil, pada saat itu kartini tidak diizinkan untuk memperoleh pendidikan yang tinggi seperti saudara laki-lakinya yang dapat melanjutkan sekolah hingga masuk ke universitas di Belanda. Hal itu membuat kartini keluar dari sekolah dan berdiam diri dirumah selama 4 tahun dalam masa pingitan. Akhirnya, kartini menumbuhkan keinginan yang dirasa kurang baik itu melalui pendidikan, dengan membangun sekolah untuk anak perempuan di daerahnya (Melati,2020:10).

\subsection{Aliran-Aliran Feminisme}

Menurut Silaban \& Punuh, (2011) terdapat beberapa aliran-aliran feminisme yang hadir pada masa postmodern yaitu:

\section{a. Feminisme Radikal}

Feminisme hadir pada abad ke 19 yang mengangkat isu utama yaitu melawan legitimasi budaya patriarki untuk mengkritisi gerakan feminis liberal yang kurang intens dan dramatis. Sebagai fokus perkembangan ideologis, feminisme memandang gender, seks dan reproduksi sebagai alasan mendasar penindasan terhadap perempuan. Namun, dengan munculnya berbagai pemikiran, komunitas feminis radikal dibagi menjadi dua kelompok yaitu feminisme liberal radikal dan feminisme radikal budaya.

b. Feminisme Liberal

Feminisme liberal muncul pada abad ke-19, menunjukan bahwa kebebasan berakar pada akal dan pemisah ruang privat dan publik, mereka mempunyai aktivitas yang tidak dapat dilihat oleh lawan jenisnya. Karena pada dasarnya perempuan adalah makhluk sosial yang memiliki kemampuan setara dengan laki-laki, maka mereka harus diberi hak yang sama dengan laki-laki.

\section{c. Feminisme Postmodern}

Gerakan feminis postmodern hadir untuk mengkritik diri sendiri terhadap patriarki atau sistem sosial yang menempatkan laki-laki sebagai pemegang kekuasaan utama. Gerakan ini bertujuan untuk mendekontruksikan budaya perempuan melalui ikon perempuan baru yang kuat dan tangguh. Dengan itu perempuan, harus memiliki kebebasan dengan tidak dibatasi dengan satu sudut pandang, apalagi dibatasi oleh definisi tertentu.

\section{d. Feminisme Multikultural}

Tren ini muncul pada tahun 1960, bagi para feminis multikultural bahwa setiap wanita memiliki pengalaman yang berbeda bagi setiap orangnya. Aliran ini percaya bahwa dengan meningkatkan kesadaran akan kepedulian, mempelajari apa yang belum pernah mereka pelajari sebelumnya dalam hidup juga berisiko. Berbekal pengetahuan ini, dimungkinkan untuk membuat perubahan sosial menuju masyarakat yang adil gender.

\subsection{Arsitektur Feminisme}

Menurut Cronin (2018) arsitektur feminisme merupakan studi yang mempelajari tentang mendesain suatu objek dengan mengadopsi dibalik sifat feminim. Dimana biasanya dalam mendesain suatu objek didominasi oleh laki-laki, maka dari itu perempuan menuntut kesetaraan dengan melakukan beberapa gerakan feminisme. Sedangkan menurut Silaban \& Punuh (2011) feminisme itu sendiri memiliki makna dalam bidang arsitektur yaitu selain pengadopsian dari sifat perempuan, feminisme memiliki arti yang lebih dalam yaitu kebebasan dan kesetaraan dalam mengekspresikan ide dan desain bangunan.

\subsection{Prinsip-prinsip Arsitektur Feminisme}


Adapun prinsip-prinsip arsitektur feminisme pada bangunan, menurut Silabah \& Punuh (2011) sebagai berikut:

\begin{tabular}{|c|c|c|}
\hline No. & Prinsip Arsitektur Feminisme & Keterangan \\
\hline 1. & $\begin{array}{l}\text { Bentuk Bangunan yang } \\
\text { mengadopsi lekukan tubuh } \\
\text { perempuan }\end{array}$ & $\begin{array}{l}\text { Bentuk bangunan arsitektur feminisme } \\
\text { biasanya menggunakan ciri-ciri dari sifat } \\
\text { keperempuanan yang elegan, dinamis serta } \\
\text { berestetika baik. Sehingga terciptalah bentuk } \\
\text { bangunan yang melengkung, tidak teratur serta } \\
\text { tidak mempunyai sudut. hal itu biasanya } \\
\text { mengadopsi dari lekukan tubuh perempuan. } \\
\text { Selain itu, aksesoris yang sering digunakan } \\
\text { perempuan juga dapat dijadikan sebuah ide } \\
\text { desain untuk merancangan sebuah objek } \\
\text { bangunan. }\end{array}$ \\
\hline 2. & $\begin{array}{lrr}\text { Fasad } & \text { Bangunan } & \text { Yang } \\
\text { Berlekuk Sebagai } & \text { Wujud } \\
\text { Kelembutan Sifat Perempuan } \\
\text { Dan Terlibatnya } & \text { Kegiatan } \\
\text { Wanita Di Dalam } & \text { Konsep } \\
\text { Bangunan. } & \end{array}$ & $\begin{array}{l}\text { Fasad bangunan merupakan salah satu hal } \\
\text { terpenting dalam arsitektur feminisme, karena } \\
\text { dapat mempengaruhi cara pandang seseorang } \\
\text { dalam melihat bangunan tersebut. Selain itu, } \\
\text { perempuan sebagian besar gemar mendandani } \\
\text { atau merias wajahnya untuk mempercantik } \\
\text { dirinya agar telihat feminim, sehingga tampilan } \\
\text { bangunannya harus menyesuaikan konsep yang } \\
\text { digunakan, dengan menggunakan kaca atau } \\
\text { organik plastik pada bagian yang transparan. }\end{array}$ \\
\hline 3. & $\begin{array}{l}\text { Warna Feminim Pada } \\
\text { Bangunan }\end{array}$ & $\begin{array}{l}\text { Warna memegang peran penting dalam } \\
\text { arsitektur feminisme, karena warna dapat } \\
\text { mempengaruhi psikologis setiap manusia, } \\
\text { terutama bagi perempuan. Pada dasarnya setiap } \\
\text { warna memiliki arti atau makna tersendiri pada } \\
\text { suatu objek rancangan. Warna pada arsitektur } \\
\text { feminisme biasanya menggunakan warna-warna } \\
\text { feminim atau warna cerah dan lembut, seperti } \\
\text { warna kuning, ungu muda, putih, oranye, dan lain } \\
\text { sebagainya. }\end{array}$ \\
\hline 4. & $\begin{array}{l}\text { Pembagian Ruang Yang } \\
\text { Jelas Dengan Diberinya } \\
\text { Batasan Antara Laki-Laki Dan } \\
\text { Perempuan }\end{array}$ & $\begin{array}{l}\text { Para feminis menuntut adanya pembagian } \\
\text { ruang dalam arsitektur untuk meningkatkan } \\
\text { kualitas hidup mereka, seperti dalam } \\
\text { berinteraksi. Para feminis menginginkan } \\
\text { pembagian ruang yang jelas antara ruang privat } \\
\text { dan ruang publik dalam arsitektur, seperti adanya } \\
\text { dapur khusus, taman pribadi. Hal itu } \\
\text { dimaksudkan agar memenuhi kebutuhan dasar } \\
\text { akan identitas diri, merasakan kebebasan, } \\
\text { kenyamanan dan rasa aman pada perempuan. }\end{array}$ \\
\hline
\end{tabular}

Tabel 1. Prinsip-Prinsip Arsitektur Feminisme

Sumber: Silaban \& Punuh, 2011

\subsection{Pengertian Pusat kecantikan}

Menurut Hakim (2001:169) dalam Dessy (2018) mengatakan bahwa pusat kecantikan adalah wadah atau tempat yang menyediakan fasilitas khususnya bagi perempuan untuk merawat dirinya agar lebih sehat dan percaya diri dalam berinteraksi sosial. Biasanya 
perawatan yang diberikan mulai dari perawatan rambut, wajah, serta tubuh. Perawatan tersebut dilakukan secara modern yang menggunakan alat-alat yang canggih, maupun tradisional alami tanpa tindakan operasi atau bedah. Hal itu karena berbagai permasalahan kulit, seperti: jerawat, kulit yang kusam, kering, sensitif dan lain sebagainya. Adapun fungsi dari pusat kecantikan yaitu suatu fasilitas pusat pemulihan kesehatan fisik dengan memberikan relaksasi dan aktivitas menyegarkan, hal itu adalah cara meditasi bagi tubuh untuk menenangkan pikiran dan tubuh.

Ada beberapa jenis pusat kecantikan itu sendiri antara lain, salon kecantikan memberikan berbagai perawatan yaitu mulai dari perawatan rambut, perawatan kulit, perawatan tubuh, perawatan tangan dan kaki, perawatan kuku, pengaplikasian kosmetik, hair removal, dan sebagainya. kemudian klinik kecantikan yang biasanya didominasi dengan penggunaan alat-alat modern dan ditangani oleh para ahli dibidangnya, perawatan yang diberikan juga beragam. Selain itu, wadah yang memberikan fasilitas pemandian air panas yang menyehatkan bagi tubuh, di tempat ini cocok bagi seseorang yang ingin merelaksasikan dirinya dari kepenatan pekerjaan dan rutinitas sehari hari.

\section{Metode Penelitian}

Penelitian pada kali ini menggunakan metode deskripsi kualitatif, karena penelitian ini fokus pada pemahaman terhadap penerapan konsep arsitektur feminisme pada bangunan pusat kecantikan. Pada penelitian ini, metode pengambilan data dilakukan melalui data sekunder berupa studi literatur untuk memperoleh hasil penelitian. Studi literatur yang digunakan melalui browsing data di internet, membaca buku dan jurnal. Literatur yang sudah dikumpulkan kemudian di baca dan dipahami hingga menemukan benang merah atau kesimpulan untuk dijadikan landasan teori dalam penelitian ini dan kemudian dianalisis. Analisis menggunakan teknik deduktif. Studi kasus yang digunakan dalam penelitian ini yaitu Natasha Skin Care yang berlokasi di Jl. Supratman No.84, Cihaur Geulis, Kec. Cibeunying Kaler, Kota Bandung, Jawa Barat. Adapun alur dalam melakukan penelitian dapat dilihat pada gambar 1 dibawah ini.

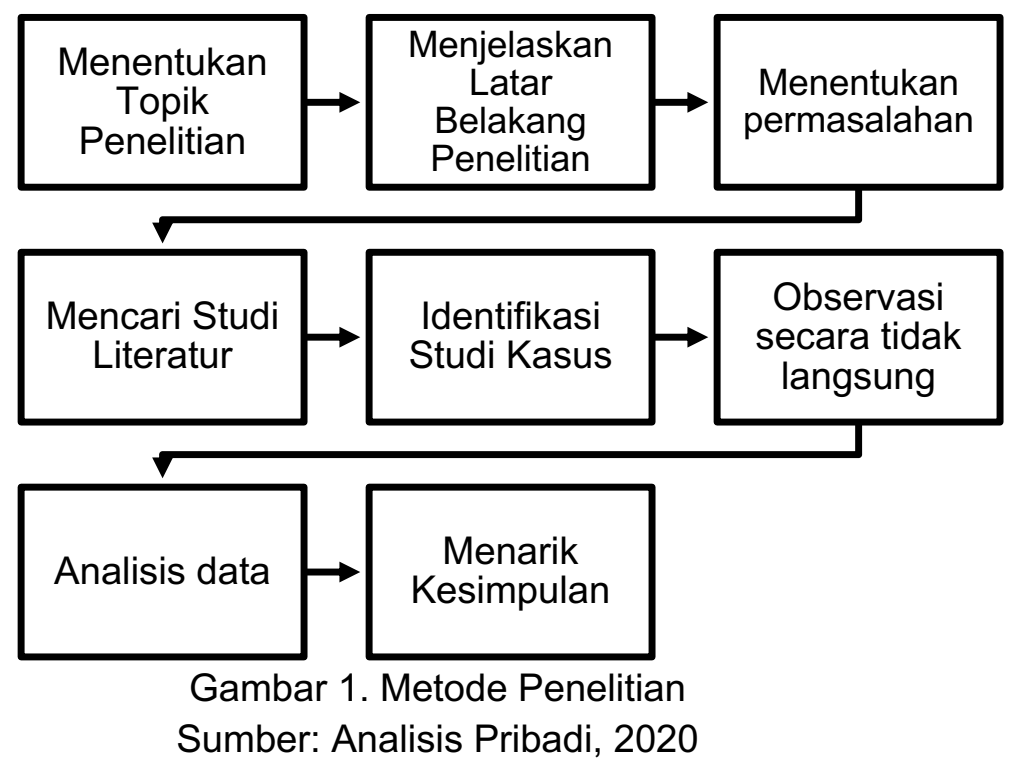

\section{Hasil dan Pembahasan}




\section{Natasha Skin Care}

Natasha skin care merupakan pelopor klinik kecantikan yang hadir pada tahun 1999, klinik pertama dibukanya Natasha Skin Care yaitu di Ponorogo Jawa Timur. Dengan menggunakan alat-alat canggih serta ditangani oleh tenaga yang sudah berprofesional membuat Natasha Skin Care berkembang dengan pesat. Hal itu karena adanya tanggapan respon positif dari pelanggan Natasha Skin Care, sehingga mampu membuka cabangcabang baru di seluruh Indonesia. Salah satunya yang berada di JI. Supratman Bandung (Natasha, 2010). Natasha Skin Cara menawarkan berbagai macam perawatan kulit antara lain, facial, peeling, botox, dan lain sebagainya.

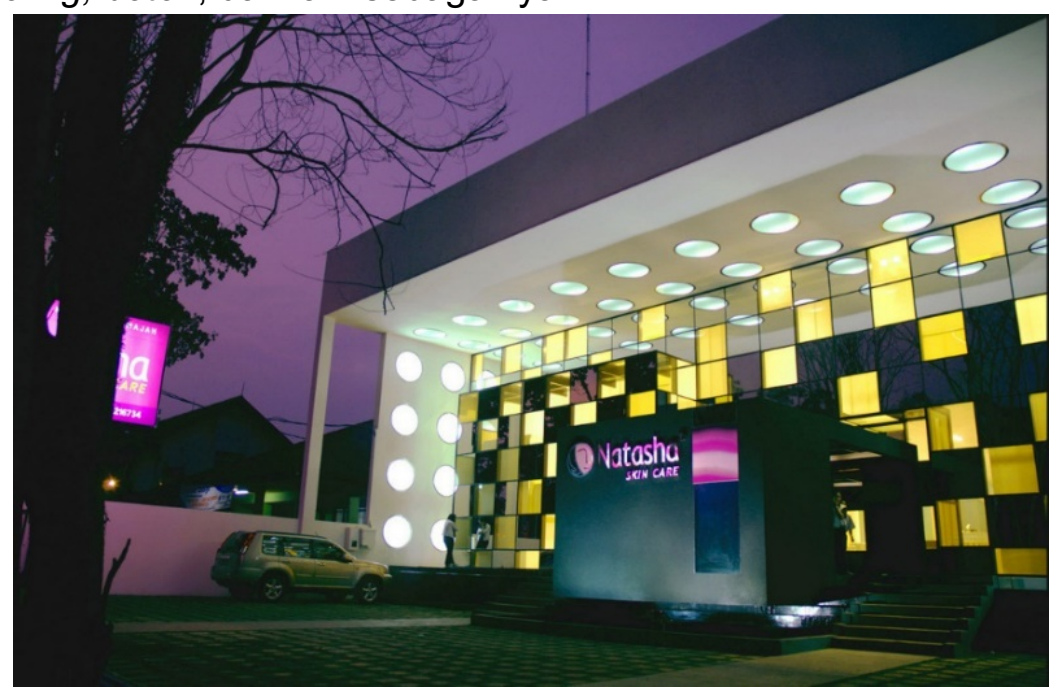

Gambar 2. Kondisi Eksisting Bangunan Natasha Skin Care

Sumber: Archdaily, 2020

\section{Deskripsi Bangunan}
Nama Bangunan
: Natasha Skin Care
Jenis
: Bangunan Komersil
Arsitek
: TWS \& Partners
Luas Bangunan
: $1000 \mathrm{~m}^{2}$
Lokasi
: Jl. Supratman No.84, Cihaur Geulis, Kec. Cibeunying Kaler, Kota Bandung, Jawa Barat.

\section{Analisis Penerapan Konsep Arsitektur Feminisme Pada Bangunan Pusat Kecantikan \\ a) Bentuk Bangunan Yang Mengadopsi Lekukan Tubuh Wanita}

Bangunan Natasha Skin Care memiliki bentuk bangunan yang datar, yaitu persegi panjang. Terbentuknya desain bangunan persegi panjang bertujuan untuk memaksimalkan kebutuhan ruang pada bangunan. Selain itu, persegi panjang melambangkan kedamaian dan kesetaraan, namun disisi lain bentuk bangunan persegi panjang dapat terlihat membosankan dan tidak menarik perhatian. Untuk menutupi sifat yang terlalu biasa pada persegi panjang, maka perancang mengkombinasikan bentuk bangunan pada fasad dengan menambahkan elemen bentuk lingkaran. Sehingga, menciptakan bangunan yang dinamis dan tidak terlihat membosankan. 


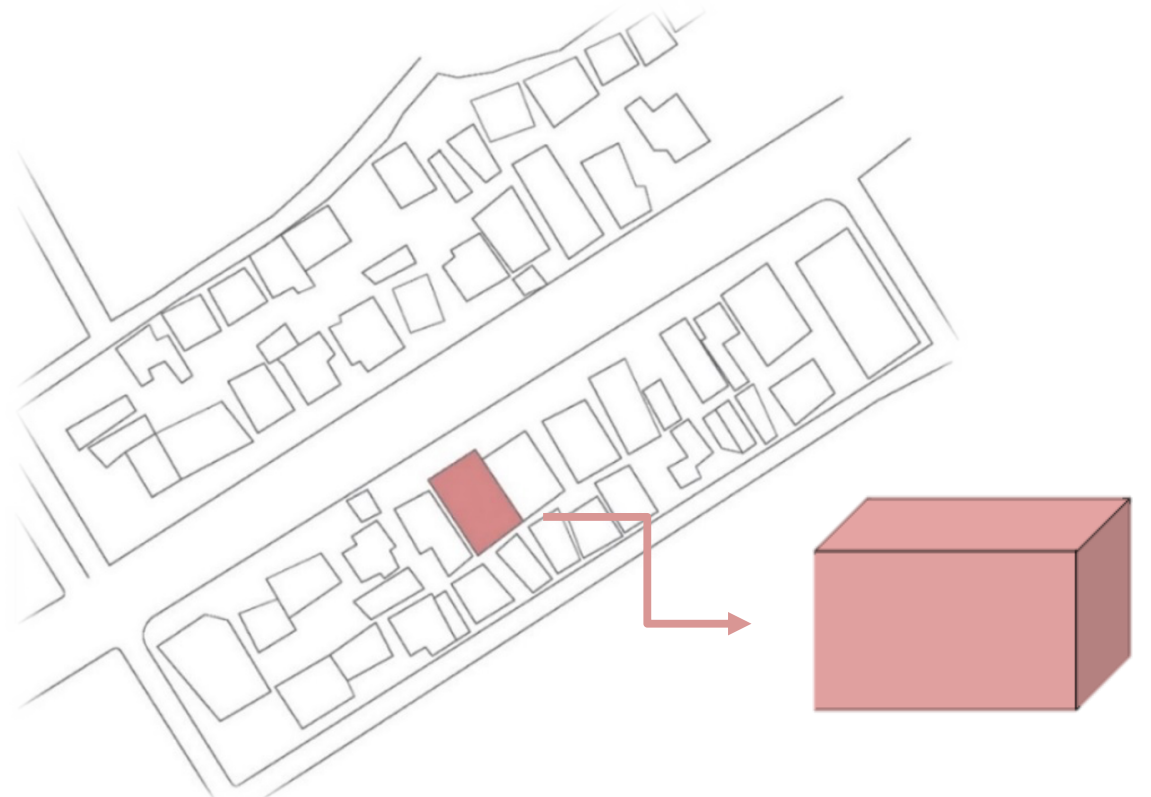

Gambar 3. Site Plan Kawasan Natasha Skin Care

Sumber: Analisis Pribadi, 2020

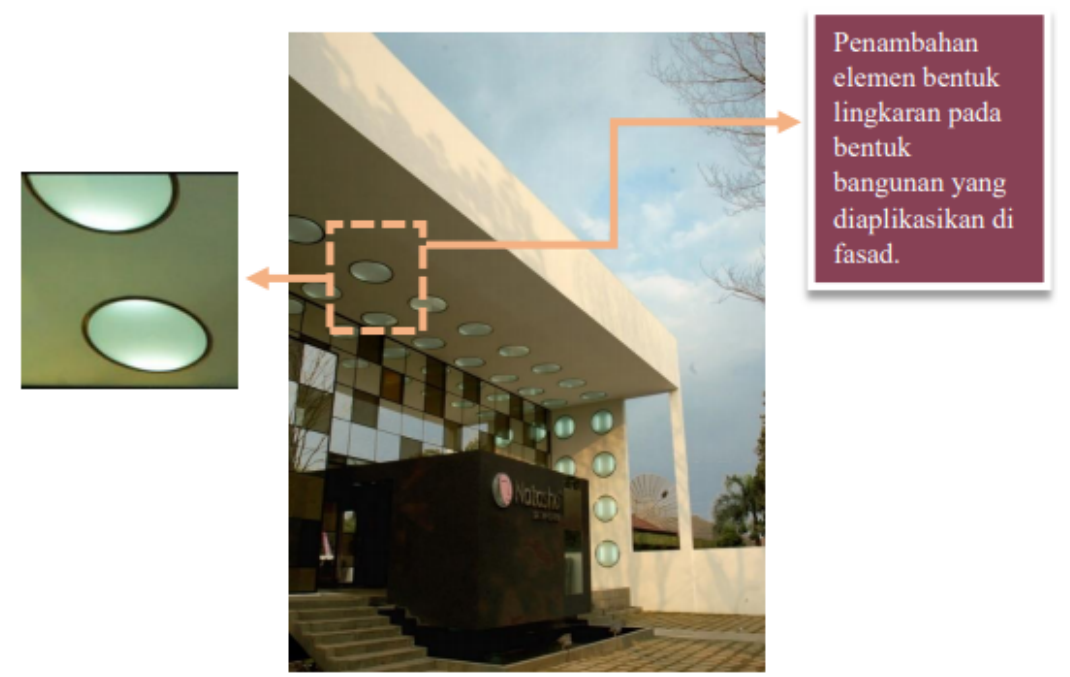

Gambar 4. Site Plan Kawasan Natasha Skin Care

Sumber: Archdaily 2020

\section{b) Fasad Bangunan Yang Berlekuk Sebagai Wujud Kelembutan Sifat Perempuan Dan Terlibatnya Kegiatan Perempuan Di Dalam Konsep Bangunan}

Fasad bangunan natasha skin care berbentuk kotak dan tegak yang terlihat monoton, karena tidak memiliki lekukan atau stream line pada fasad. Namun, pada bagian yang transparan, bangunan ini menggunakan dua jenis kaca yang digunakan pada fasad yaitu perpaduan kaca laminasi yang dilapisi kaca film dengan menggunakan warna kuning dan cermin yang dicampur secara acak. Hal ini terlihat pada desain fasad yang mengadopsi kegiatan perempuan dalam bidang kecantikan, karena pada dasarnya sebagian besar perempuan berlomba-lomba dalam mempercantik dirinya dengan mendandani wajahnya. 
Fasad

berbentuk kotak dan tegak.

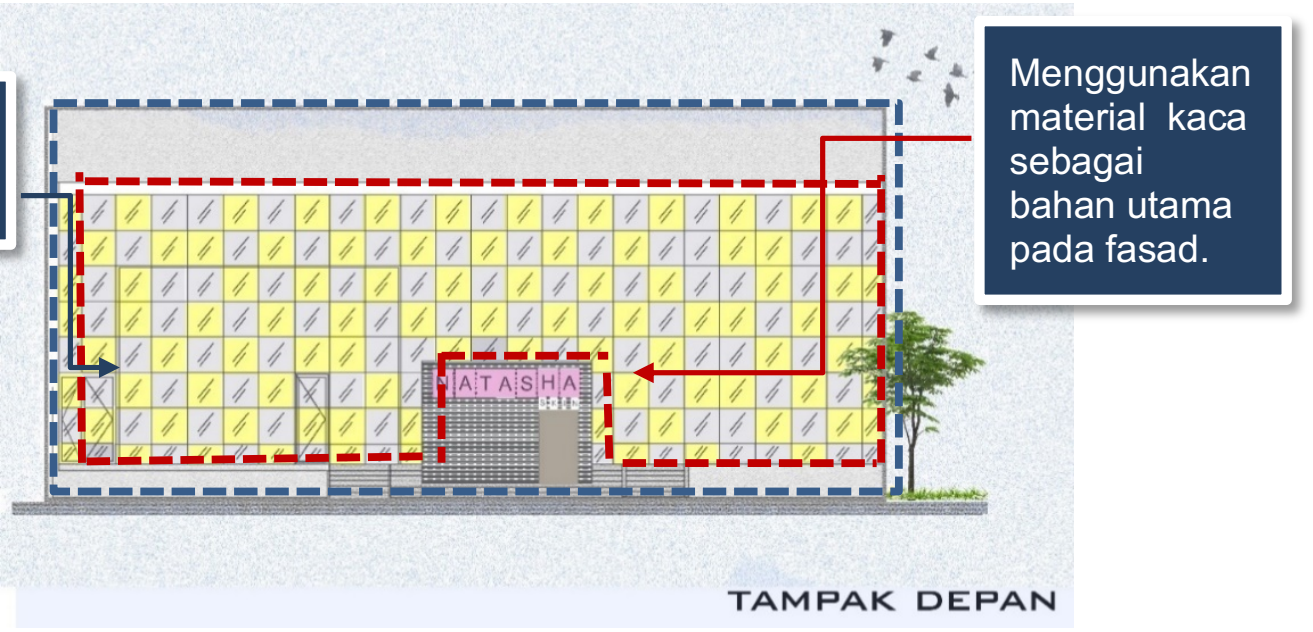

Gambar 5. Site Plan Kawasan Natasha Skin Care Sumber: Analisis Pribadi, 2020

Walaupun fasadnya tidak memiliki lekukan pada sudut bangunan, namun fasad menggunakan material kaca pada bagian yang transparan. Perpaduan kaca laminasi dan cermin membuat bangunan natasha skin care memiliki karakteristik yang unik di antara bangunan disekitarnya. Kaca laminasi yang dilapisi kaca film berwarna kuning tidak hanya sekedar sebagai pemanis tampilan, namun berfungsi untuk mengatur temperatur pada bagian dalam bangunan agar tidak terlalu panas pada siang hari.

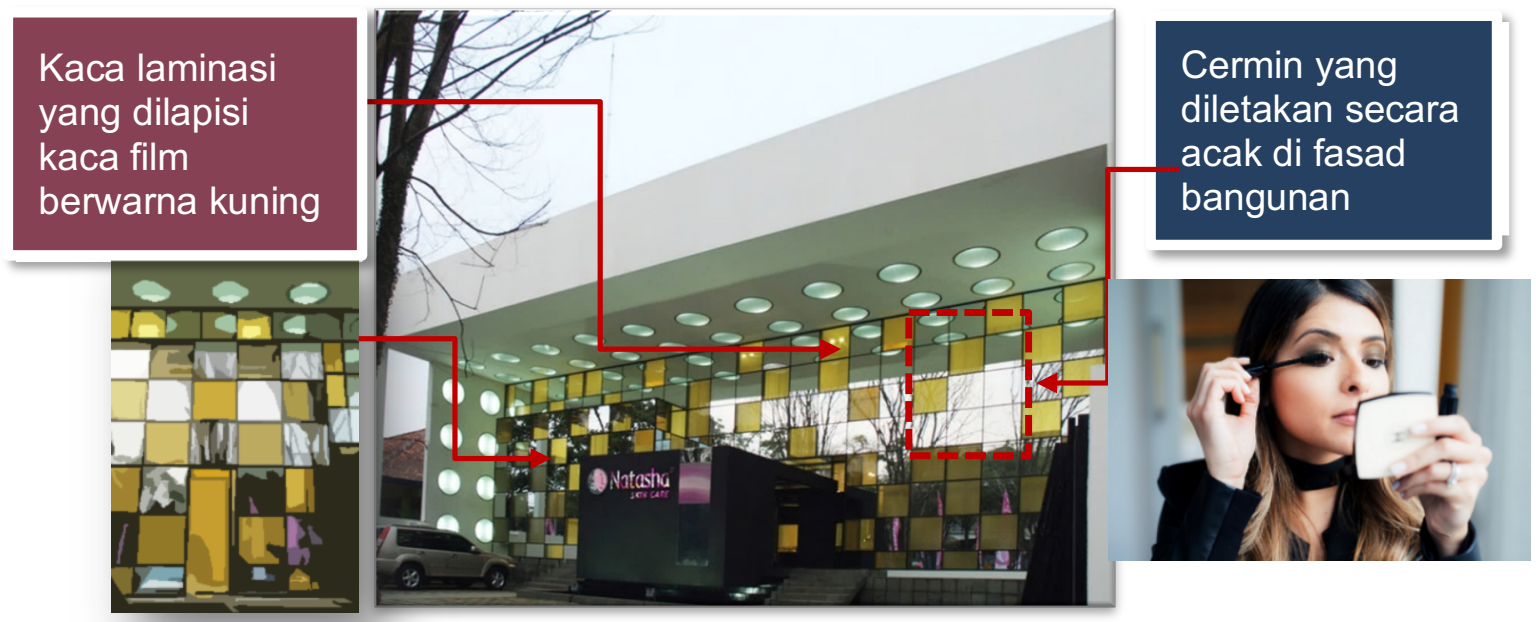

Gambar 6. Fasad Plan Kawasan Natasha Skin Care

Sumber: Analisis Pribadi, 2020

\section{c) Warna Feminim Pada Interior Dan Eksterior}

Interior pada bangunan natasha skin care memiliki warna yang beragam, mulai dari warna putih digunakan sebagai warna dasar atau warna dominan pada bangunan Natasha Skin Care. Warna putih diterapkan pada dinding di setiap ruangnya dengan dipadukan warna ungu pada kain selimut dan kasur berwarna putih memberikan kesan ketenangan namun terlihat lebih anggun seperti pakaian yang dikenakan perempuan pada gambar 6 dibawah ini. Hal itu membuktikan interior pada ruang treatment, menggunakan warna feminim seperti adanya warna ungu. 


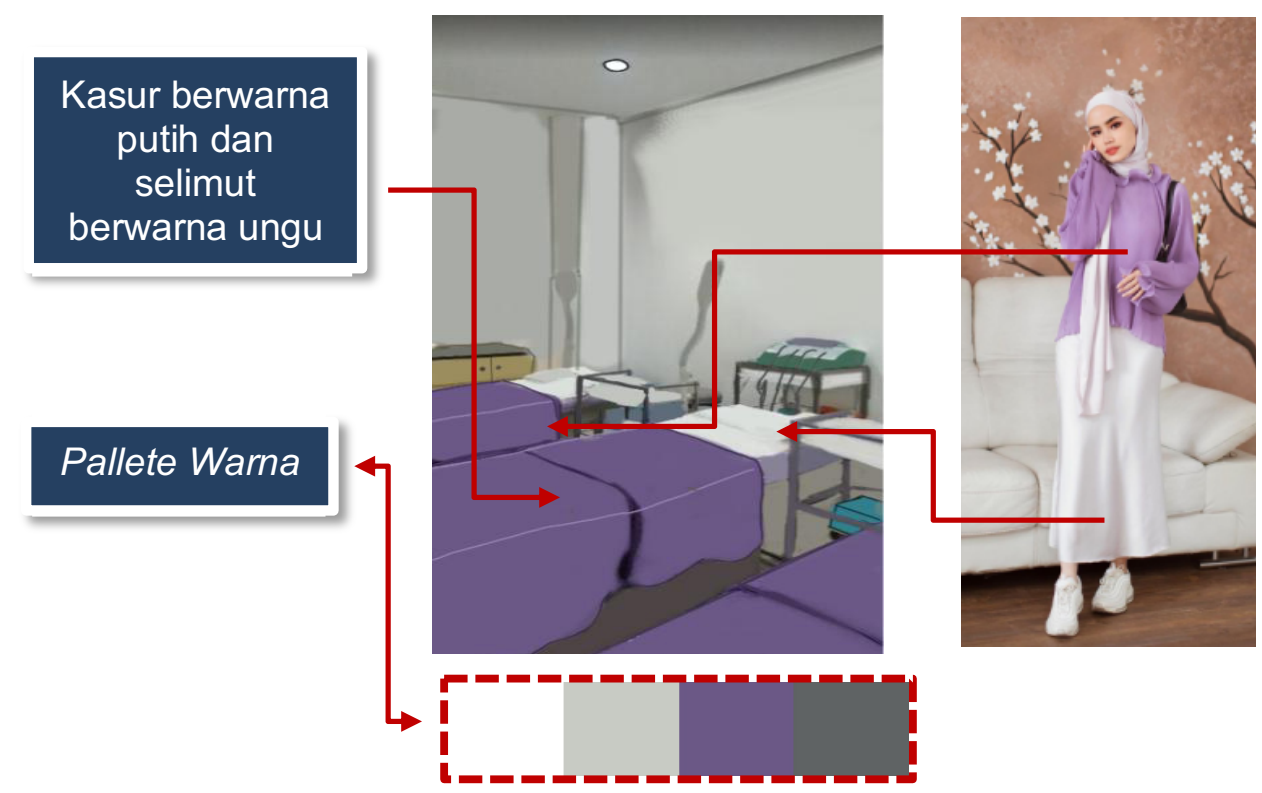

Gambar 7. Ruang Treatment Natasha Skin Care

Sumber: Analisis Pribadi, 2020

Walaupun didominasi oleh warna putih, setiap ruangan pada bangunan natasha skin care memiliki warna yang mencolok. Seperti tempat registrasi dan kasir pada lantai dasar, menggunakan perpaduan warna kuning seperti dress yang digunakan pada perempuan dan warna hitam. Warna kuning digunakan pada ornamen plafon LED di bagian tempat pendaftaran. Serta terdapat warna hitam yang melapisi furniture seperti kursi dan meja kasir.

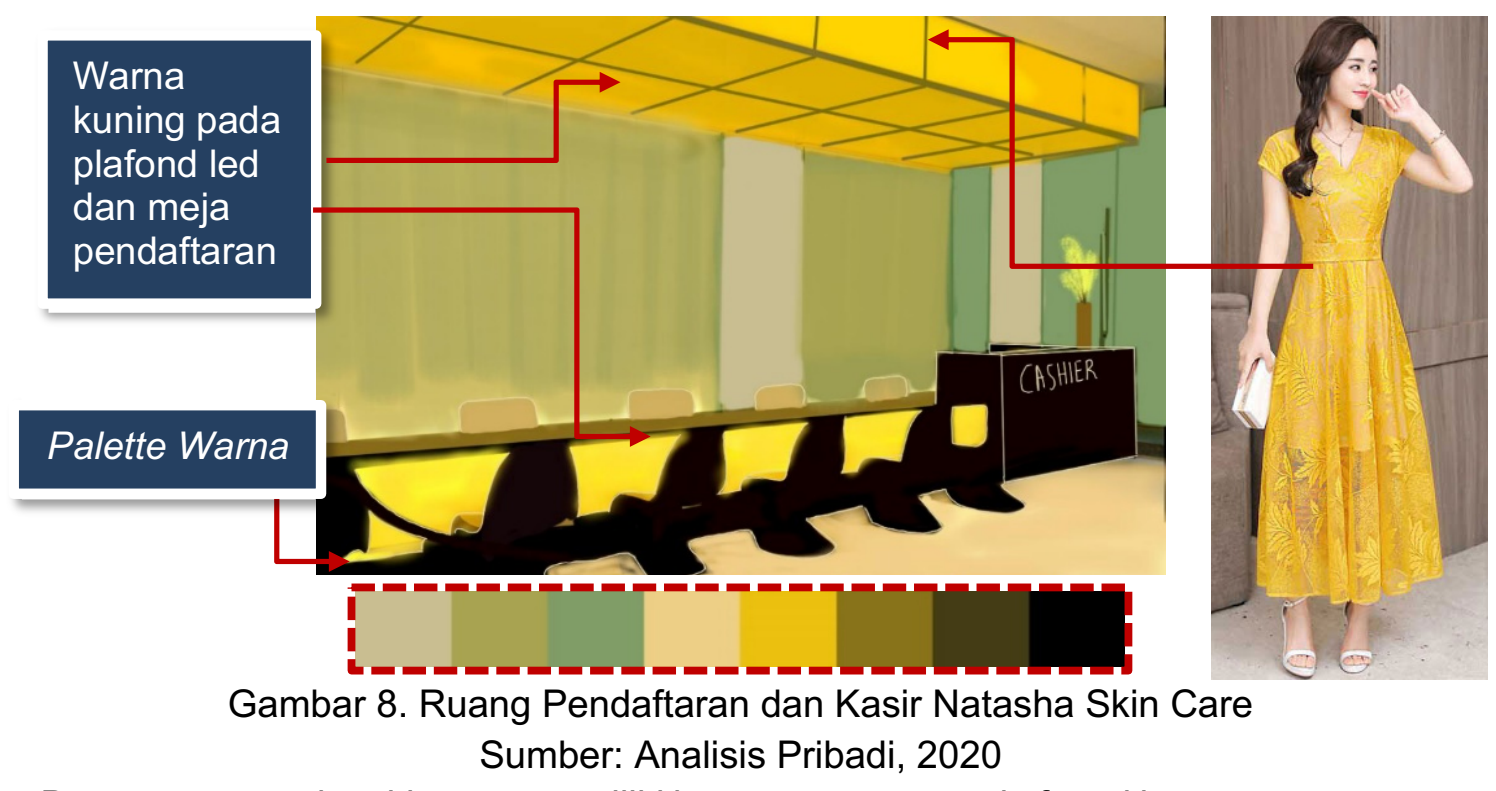

Bangunan natasha skin care memiliki beragam warna pada fasad bangunannya, seperti warna kuning, ungu, putih, dan hitam. Warna tersebut dikombinasi menjadi satu kesatuan pada fasad bangunan, warna kuning pada kaca laminasi melambangkan sifat kulit manusia yang transparan. Sedangkan warna logo natasha skin care memiliki arti yang spesifik yaitu warna ungu. Selain itu warna hitam digunakan pada ruang satpam dan warna putih yang 
melapisi bagian atap dak bangunan. Warna tersebut merupakan warna-warna feminim seperti kuning, ungu dan putih, sehingga dapat dikatakan interior maupun eksterior bangunan Natasha Skin Care sudah menerapkan warna konsep arsitektur feminisme yaitu warna-warna yang cerah.

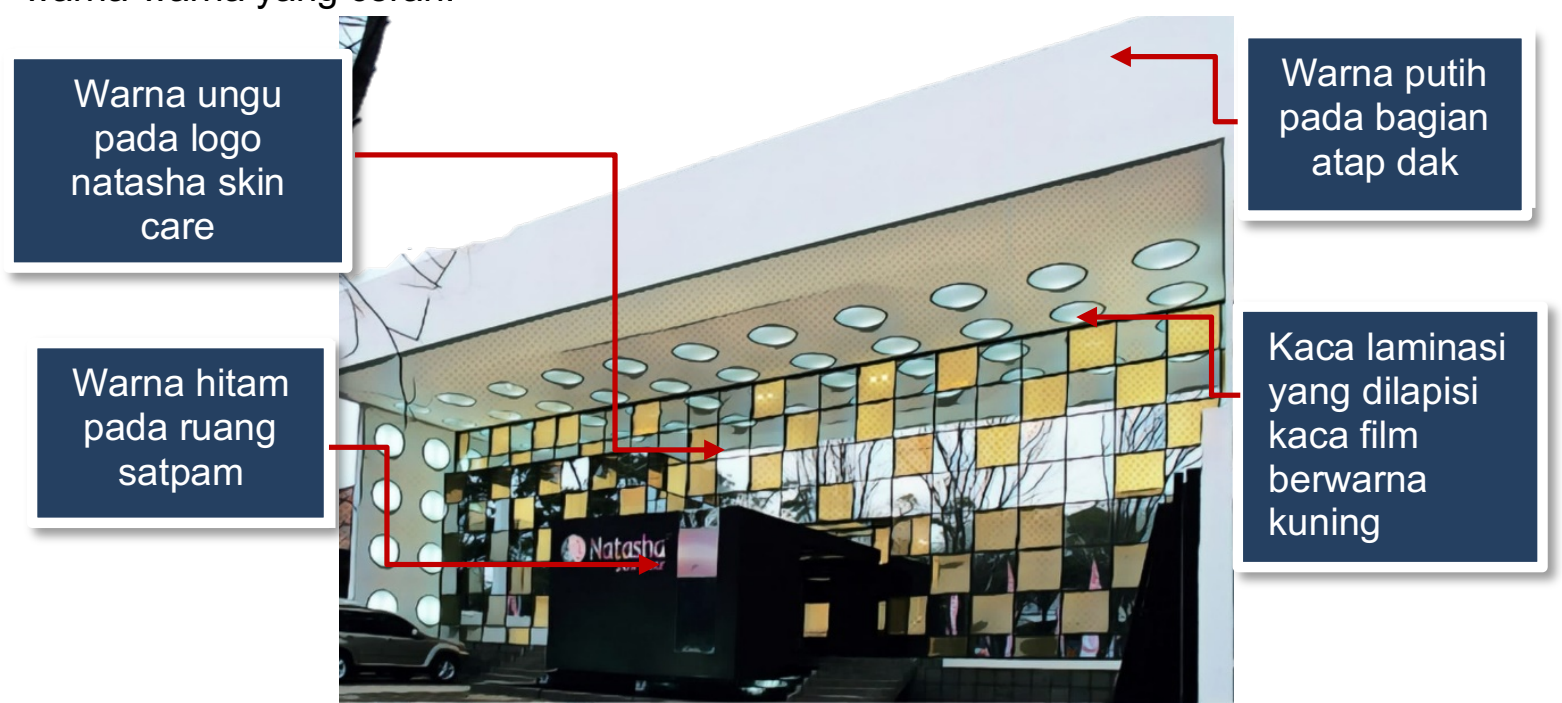

Gambar 9. Warna Fasad Bangunan Natasha Skin Care

Sumber: Analisis Pribadi, 2020

\section{d) Pembagian Ruang Dengan Diberi Batasan Antara Laki-Laki Dan Perempuan Pada Area Privat}

Bangunan natasha skin care dibagi menjadi enam area meliputi, area publik (zona hijau) seperti adanya teras, ruang tunggu, serta drugstore. Kemudian area semi publik (zona coklat) seperti ruang satpam yang terletak di bagian depan bangunan. Lalu area privat (zona merah) seperti ruang administrasi yang merupakan tempat menyimpan hasil rekapan data pasien, ruang penyimpanan, ruang penyimpanan kartu pasien, kamar tidur, serta tempat khusus untuk dokter. Selain itu area semi privat (zona biru) seperti adanya ruang loker khusus pegawai, tempat kasir, pendaftaran, resepsionis serta ruang untuk melakukan perawatan body whitening dan laser untuk pasien. Dan yang terakhir yaitu area servis seperti adanya ruang makan khusus pegawai dan dokter, toilet, pantry serta lavatory. Pembagian ruang menentukan zona area pada bangunan dengan adanya dinding sebagai pembatas ruang. Hal itu dapat menunjukan bahwa adanya kejelasan pada setiap ruang, terbentuknya zona area dari kebutuhan ruang dan terciptanya dinding sebagai pembatas menjadikan ruang tersebut berfungsi sesuai dengan kebutuhannya. 


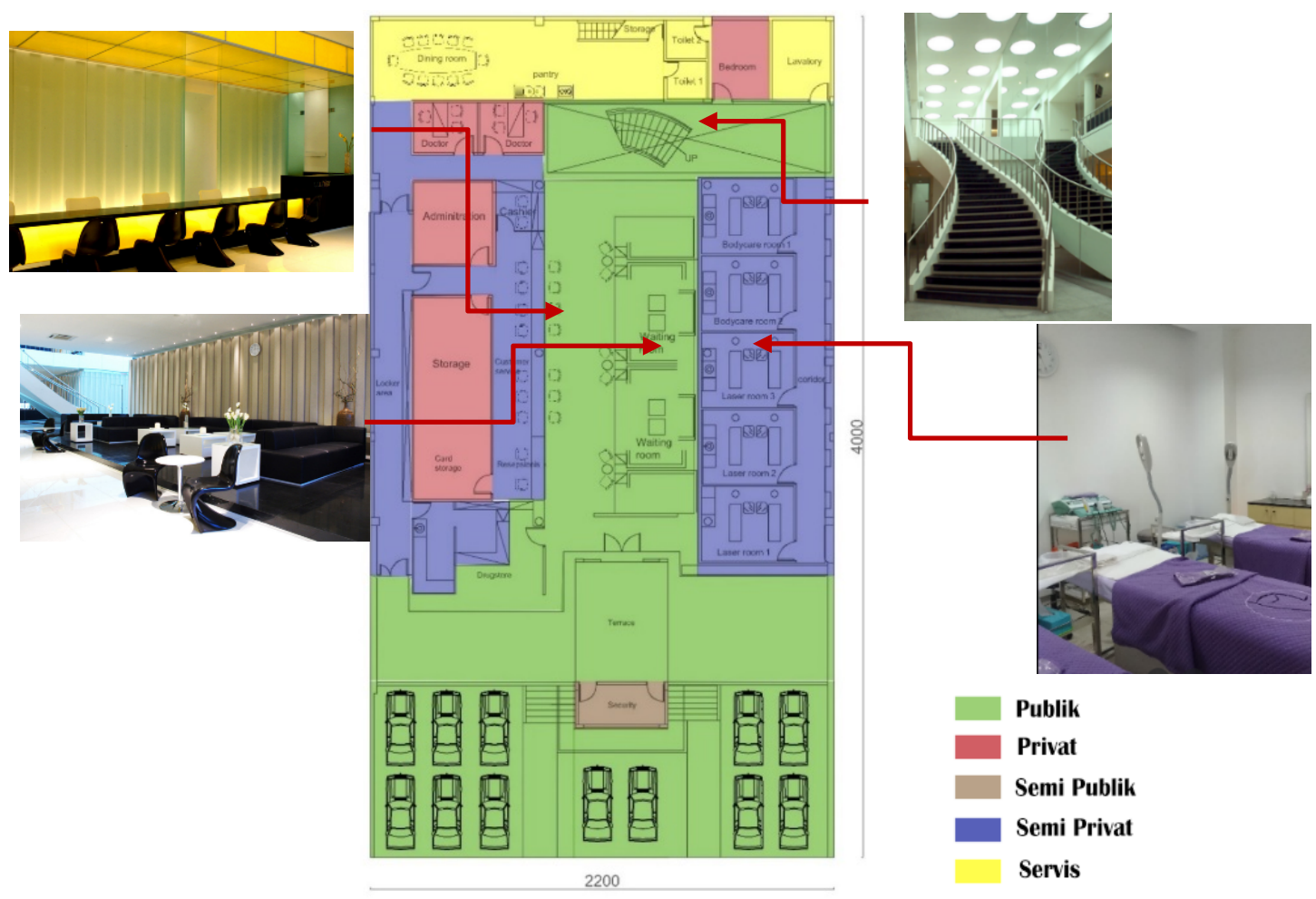

Gambar 10. Warna Fasad Bangunan Natasha Skin Care

Sumber: Analisis Pribadi, 2020

Bangunan natasha skin care terdiri dari dua lantai yang dibagi menjadi beberapa area, di lantai kedua didominasi dengan ruang-ruang yang digunakan untuk melakukan berbagai perawatan. Area publik pada lantai dua (zona hijau) pada lantai dua seperti adanya musholla dan ruang tunggu, kemudian area semi publik (zona cokelat) adanya koridor yang menghubungkan ke ruang-ruang perawatan. Sedangkan, area semi privat (zona biru) terdapat ruang body whitening serta kamar mandi khusus yang difasilitasi sebagai penunjang setelah melakukan perawatan tersebut dan adanya 14 ruang treatment untuk pasien melakukan perawatan umum yang dibutuhkan. Selain itu, adanya area service (zona kuning) seperti lavatory. 


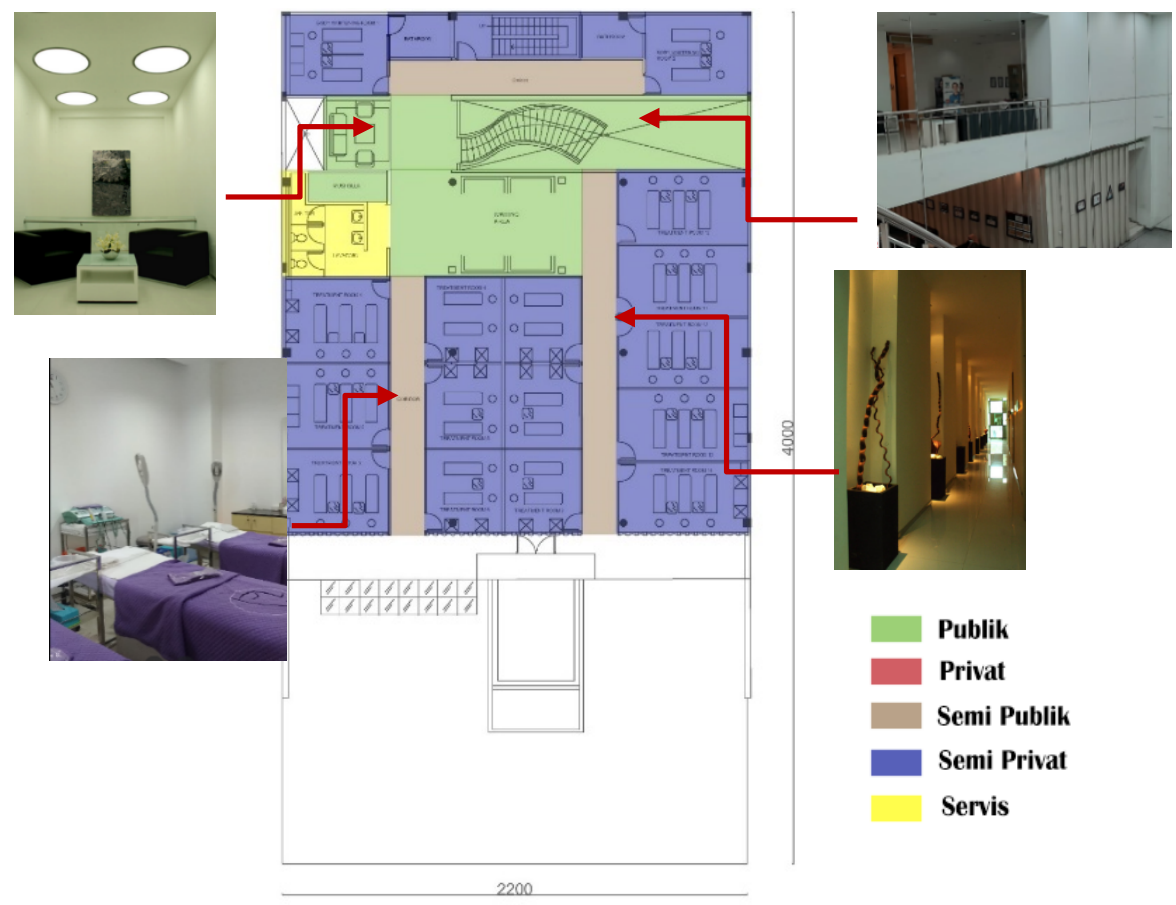

Gambar 11. Warna Fasad Bangunan Natasha Skin Care Sumber: Analisis Pribadi, 2020

\section{Kesimpulan}

Kesimpulan yang sudah didapatkan dari penelitian diatas yaitu arsitektur feminisme ialah ilmu yang mengadopsi ciri-ciri sifat perempuan dalam merancang suatu objek dengan mengekspresikan ide dan desain bangunan yang bertujuan untuk membuat perempuan merasakan kebebasan dan kenyamanan pada suatu bangunan.

Penerapan arsitektur feminisme pada pusat kecantikan dapat dilihat dari bentuk bangunan yang memiliki lekukan pada setiap sudutnya, dengan mengadopsi lekukan tubuh perempuan. Hal itu bertujuan agar bangunan tersebut tidak terlihat monoton, sehingga terciptanya karakteristik dari bangunan tersebut, seperti yang diterapkan oleh bangunan Erha Derma Center yang memiliki bentuk bangunan melengkung. Pada studi kasus Natasha Skin Care, bangunan ini memiliki bentuk persegi panjang yang membuat bangunan Natasha Skin Care terlihat monoton dengan tidak memiliki lekukan-lekukan seperti tubuh perempuan. Kemudian fasad bangunan didominasi dengan menggunakan material kaca seperti pada salah satu alat kosmetik perempuan, terdapat dua jenis kaca yang digunakan yaitu kaca cermin yang diaplikasikan secara acak, dan kaca laminasi yang dilapisi dengan kaca film berwarna kuning. Lalu eksterior dan interior bangunan menggunakan warna-warna yang cerah seperti warna kuning dan putih. Pembagian ruang privat dan publik diberi pembatas dinding sebagai bentuk kejelasan pada setiap ruang, namun bangunan ini tidak memiliki batasan antara ruang untuk wanita dan ruang untuk lakilaki. Hal tersebut dapat dikatakan bahwa bangunan Natasha Skin Care hampir mendekati penerapan konsep arsitektur feminisme. 


\section{Daftar Pustaka}

Archdaily. (2009, 07 23). Natasha Skin Care / TWS \& Partners. From Archdaily: https://www.archdaily.com/29795/natasha-skin-care-twspartners?ad source=search\&ad medium=search result all

Badu, R., Egam, \& Rompas, L. M. (2019). Beauty mall di Manado "Arsitektur Feminisme". Jurnal arsitektur daseng unsrat Manado.

Cronin, Elizabeth. 2018. Architecture and Feminism: Discussions towards Inclusive Ideologies, Pedagogies, and Practices. Florida: Thesis of Florida University.

Dessy, V. (2018). BEAUTY CARE CENTRE DI KOTA PONTIANAK. Jurnal online mahasiswa Arsitektur Universitas Tanjungpura, 293-305.

Majidah, Hasfera, D., \& Fadli, M. (2019). Penggunaan Warna Dalam Desain Interior Perpustakaan Terhadap Psikologis Pemustaka. Ristekdikti (Jurnal Bimbingan dan Konseling), 95-106.

Melati, N. K. (2020). Membicarakan Feminisme. Yogyakarta: EA Books.

Pangkey, C., Rogi, O. H., \& Siregar, F. O. (2017). Oceanarium Di Manado "Estetika Kaca Pada Bangunan Dengan Penerapan Arsitektur Feminisme. Jurnal Arsitektur DASENG UNSRAT Manado, 112-120.

Saidul, A. (2013). Pasang Surut Gerakan Feminisme . Marwah Vol. XII No. 2, 146-156.

Silaban , C. V., \& Punuh, C. S. (2011). Arsitektur Feminisme. Media Matrasain, 29-39.

Sri, N. P., Nugroho, W. B., \& Anggita, N. M. (2020). Feminisme posmodern luce irigaray: pembebasan perempuan dari bahasa patriarki. Jurnal Ilmiah Sosiologi Vol 01 No 1.

Sya'bania, S. R., Mauliani, L., \& Sari, Y. (2019). Adaptasi Bentuk Bangunan Pusat Pemberdayaan Ekonomi Perempuan Di Bekasi Terhadap Kondisi Lahan. Jurnal arsitektur PURWARUPA, 57-64. 